\title{
Dissolved Inorganic Carbon (DIC) Contents in Middle and Lower Reaches of Lancang River: Related to Water Environments and Dams
}

\author{
Jinxia Lu, Kaidao Fu*, Mingyue Li, Daxing Li, Di Li, Chao Wang, Wenhui Yang \\ Yunnan Key Laboratory of International Rivers and Transboundary Eco-Security, Asian International Rivers Center, \\ Yunnan University, Kunming, China \\ Email: *kdfu@ynu.edu.cn
}

How to cite this paper: Lu, J.X., Fu, K.D., Li, M.Y., Li, D.X., Li, D., Wang, C. and Yang, W.H. (2017) Dissolved Inorganic Carbon (DIC) Contents in Middle and Lower Reaches of Lancang River: Related to Water Environments and Dams. Journal of Water Resource and Protection, 9, 1132-1144. https://doi.org/10.4236/jwarp.2017.910074

Received: August 8, 2017

Accepted: September 15, 2017

Published: September 18, 2017

Copyright $\odot 2017$ by authors and Scientific Research Publishing Inc. This work is licensed under the Creative Commons Attribution International License (CC BY 4.0).

http://creativecommons.org/licenses/by/4.0/

(c) $\underset{\mathrm{EY}}{0}$ Open Access

\begin{abstract}
Carbon cycle is one of the focuses of climate change, river carbon is an important part, while dissolved inorganic carbon (DIC) has a high proportion of river carbon flux. In this study, we did the research on the Lancang River, an important international river in the southwest of China. Water samples were obtained from 16 sections of the middle and lower reaches of the Lancang River in 2016 (11 months), then we monitored some water quality indicators and DIC content, finally analyzed the temporal-spatial distribution characteristics of DIC and the relationship between DIC content and water environment factors. The results showed that: (1) DIC contents in the middle and lower reaches of the Lancang River varied from $1.1840 \mathrm{mmol} / \mathrm{L}$ to 3.1440 $\mathrm{mmol} / \mathrm{L}$, with a mean value of about $2.2155 \mathrm{mmol} / \mathrm{L}$. (2) At a time scale, DIC contents of dry season (spring, autumn and winter) were higher than rainy season (summer). At a space scale, DIC contents of the middle and lower reaches of the Lancang River gradually decreased from north to south, and each reservoir had the same characteristics, that is, DIC contents at upstream of the dam was lower than those at downstream of the dam. Compared to other rivers with cascade dams around the world, DIC contents within studied river were at similar level. And the reservoir's effect of the Lancang River were not obvious, however, DIC contents in the water sampled upstream the dams had a slight stratification. (3) Water temperature, conductivity, turbidity were important factors affecting DIC content of water, and the effect of oxidation and reduction potential (ORP) and $\mathrm{pH}$ on DIC was relatively small.
\end{abstract}

\section{Keywords}

Lancang River, DIC Content, Spatial-Temporal Differentiation, Water Environments, Dams 


\section{Introduction}

At present, with rapid development of global society and economy, many environmental problems have appeared. Among them, global warming has become one of the most important environmental problems and most serious challenges. Many studies have showed that human activities lead to escalating content of greenhouse gas (mainly $\mathrm{CO}_{2}$ and $\mathrm{CH}_{4}$ ) since the late of 20th century, which results in greenhouse effect, that is, rises of surface temperature and global warming [1] [2] [3]. So global carbon cycle has become a hotspot about global change research, the importance of carbon cycle research is not only a hot topic in the international scientific research, but also has important practical significance [4] [5].

Rivers are important parts of global carbon cycle research and are playing a role as an important link between land and marine ecosystems. The carbon in river ecosystem is mainly composed of DIC (dissolved inorganic carbon), DOC (dissolved organic carbon), POC (particulate organic carbon) and PIC (particulate inorganic carbon) [6]. Among them, dissolved inorganic carbon (DIC) is an important component of river carbon flux (accounts for more than $90 \%$ in southwest of China), which is related to the process of carbon transportation between river and ocean system. It is also a key to analyze the global carbon cycle. Rivers transport large amounts of dissolved inorganic carbon to the ocean each year, and these are very important for the various branches research of marine science. The $\mathrm{CO}_{2}$ system, formed by DIC's major components through a series of thermodynamic equilibrium, played an important role on the buffering of water $\mathrm{pH}$ value and the indication of the photosynthesis and respiration of river water ecosystem. In addition, DIC content would affect the water $\mathrm{pCO}_{2}$ and exchange fluxes of water-gas interface. Combining water chemistry data with isotopes of carbon is an important method to reveal the process of substance circulation in rivers and reservoirs [7] [8] [9]. Since the 1980s, a number of studies on the river DIC content at home and abroad have started to aim at independent or individual rivers and watersheds [10] [11] [12].

Most of researches on the Lancang River focused on its hydrological and water resources after the construction of hydropower station, changes of the water ecological environment [13], land use, the changes of fishes [14], temporal and spatial distribution of heavy metals and other elements such as nutrients [15] [16], sediment response [17], and phytoplankton [18] [19] and so on, while less researches on DIC content. Due to the large-scale hydropower development, the middle and lower reaches of the Lancang River had currently become the real cascade of the development of "impounding rivers" which was best area to study internal biogeochemical cycle (the nutrient elements) of the "river-reservoir-river" system. Therefore, the study analyzed DIC content in the middle and lower reaches of the Lancang River and its chemical characteristics, studied carbon geochemical behavior of river-reservoir in the Lancang River Basin, then clarified the content and temporal-spatial characteristics of DIC in the Lancang River 
and its controlling factors after the interception of the cascade reservoir, finally provided a scientific basis for further explaining the evolutionary processes and characteristics of rivers after the interception of dam.

\section{Monitoring Data and Analysis Methods}

\subsection{Study Area}

The Lancang-Mekong River is an important international river, which originates from Qinghai in China. The watershed covers six countries: China, Laos, Myanmar, Thailand, Vietnam and Cambodia. Finally the river with a total length of $4880 \mathrm{~km}$ flows into the South China Sea in Vietnam. The river is the sixth longest river in the world and the third longest international river, which is located in the center of the five continents of the world with rich water resources, biological resources, mineral resources, tourism resources and national cultural resources [13].

With the north side higher than the south, the topography of different reaches in the Lancang-Mekong River Basin was totally different. The Lancang River Basin is a basically part in China, the upper and lower reaches is wider than the middle reaches, the average width of basin is about $80 \mathrm{~km}$. The climate in the Lancang River basin is very different. The temperature and rainfall are generally increasing from north to south, and the higher the altitude, the lower the temperature, the less the precipitation. The whole basin is southwest monsoon climate, the boundary between dry season (generally 5 - 10 months) and wet season (11 - 4 months) is obvious, and about $85 \%$ of the precipitation concentrated in the wet season [20].

At present, the Lancang River in Yunnan Province has been exploited by 15 classes, the upper reaches is planning 7 classes while the middle and lower reaches is proceeding 8 hydropower dams because of its load requirements, proper location, traffic conditions, terrain, geological conditions, technical and economic conditions. The stations from north to south are Gongguoqiao (GGQ), Xiaowan (XW), Manwan (MW), Dachaoshan (DCS), Nuozhadu (NZD), Jinghong $(\mathrm{JH})$, Ganlanba, Mengsong. Now 6 stations have been built with the core of Xiaowan and Nuozhadu.

\subsection{Monitoring Section and Sampling Frequency}

In view of the location of hydropower station, we select 12 points in the middle and lower reaches of the Lancang River mainstream: Miaowei (MW), Upstream of the Gongguoqiao dam (UGGQ), Downstream of the Gongguoqiao dam (DGGQ), Upstream of the Xiaowandam (UXW), Downstream of Xiaowan dam (DXW), Jiajiu hydrological station (JJZ), Dachaoshan hydrological station (DCS), Jinglin Bridge (JLQ), Upstream of the Nuozhadudam (UNZD), Downstream of the Nuozhadu dam (DNZD), Jinghong old bridge (JHQ), Guanlei (GL), and 4 points of the main tributaries: Dalishu (DLS), Saihandaqiao (SH), Heihereshuitang (HHR), Biyundaqiao (BYQ) (Figure 1). We monitored water 


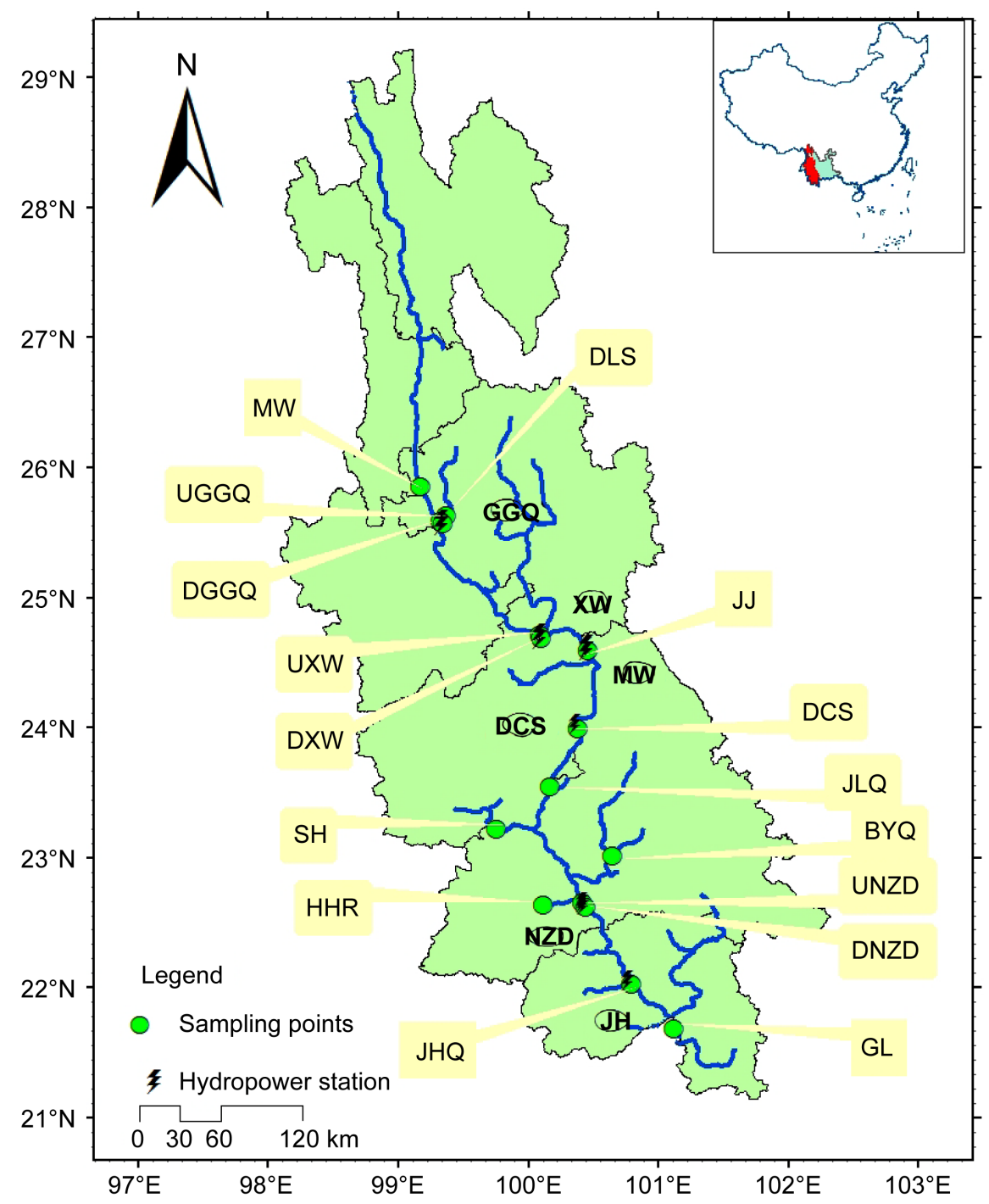

Figure 1. Sampling points map.

quality and DIC content in the middle of each month in 2016 except February due to the practical constraints (Figure 1).

\subsection{Sampling}

Water samples were collected at all sampling points with stainless steel water collection devices from surface layer (about $0.5 \mathrm{~m}-1 \mathrm{~m}$ ). The water samples used for the analysis were immediately transferred to $300 \mathrm{ml}$ or $500 \mathrm{ml}$ polyethylene bottles. In order to prevent contamination, we should rinse the polyethylene bottle three times before sampling, and the water sample must fill the bottle without bubbles.

\subsection{Experimental Determination}

Water temperature (WT), $\mathrm{pH}$, total solid suspension (TSS), conductivity (Cond), ORP and turbidity (Tur) will be measured in situ by HORIBA-U52 Potable Wa- 
ter Quality Analyzer. The river DIC typically includes $\mathrm{H}_{2} \mathrm{CO}_{3}, \mathrm{HCO}_{3}^{-}$and $\mathrm{CO}_{3}^{2-}$ components. The $\mathrm{pH}$ value of the Lancang River is $7 \sim 8$, so DIC mainly exists in the form of $\mathrm{HCO}_{3}^{-}$. Then we used content of $\mathrm{HCO}_{3}^{-}$(by method of titrimetry in situ) instead of DIC content.

\subsection{Data Analysis}

After we obtained the measured data, we would organize the data and use SPSS 20.0 and Excel to start basic statistical parameters calculation and correlation analysis, ArcGIS for graphical analysis. Finally we wanted to summarize the rule about DIC content in Middle and Lower Reaches of Lancang River and find its main influencing factors by correlation analysis.

\section{Results}

Use obtained data to analyze temporal and spatial changes of DIC content, the results are as follows.

\subsection{Seasonal Changes of DIC Content}

Data showed on Figure 2. DIC content in dry season (November-December and January-April) in the middle and lower reaches of the Lancang River is obviously higher than that of the rainy season (May-October), lowest level in October. DIC content of the middle and lower reaches of the Lancang River in rainy season was about $2.0134 \mathrm{mmol} / \mathrm{L}$, while it was about $2.3211 \mathrm{mmol} / \mathrm{L}$ in dry season, and the difference value was about $0.3078 \mathrm{mmol} / \mathrm{L}$. During the dry season, the content range ability of each month was small, about $0.1000 \mathrm{mmol} / \mathrm{L}$, and the range ability in the rainy season was higher, about $0.3000 \mathrm{mmol} / \mathrm{L}$. It is obvious that DIC content of October was significantly lower than other months because of slow moves of water. Therefore, it can be concluded that DIC content of dry season and rainy season is quite different.

In general, DIC content in the middle and lower reaches of the Lancang River varied from $1.1840 \mathrm{mmol} / \mathrm{L}$ to $3.1440 \mathrm{mmol} / \mathrm{L}$, with a mean of $2.2155 \mathrm{mmol} / \mathrm{L}$.

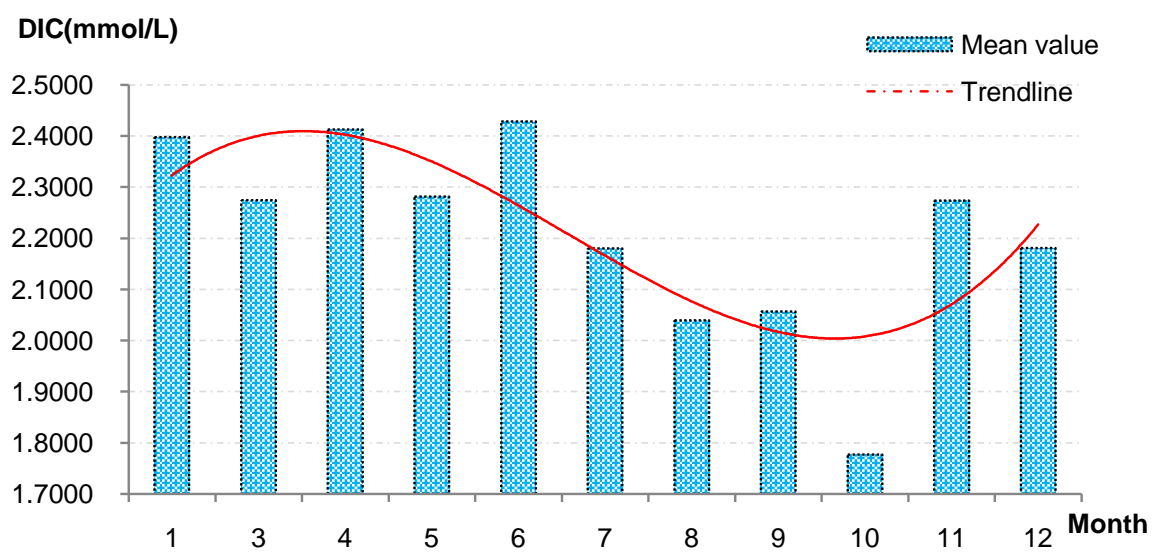

Figure 2. DIC content changes in the middle and lower reaches of the Lancang River in 2016. 
According to their different geographical environment, climate change and rainfall characteristics, DIC content of each point had its own characteristics. However, it also had the rule of dry season (spring, autumn and winter) > rainy season (summer).

\subsection{Spatial Variation of DIC Content}

According to obtained data and Figure 3, DIC content from upstream to downstream in the middle and lower reaches of the Lancang Rive gradually decreased, while the contents of UGGQ, UXW, JLQ were lower. DIC content in the upper reaches (about $2.5005 \mathrm{mmol} / \mathrm{L}$ ) was significantly higher than that in the downstream area (about $2.1533 \mathrm{mmol} / \mathrm{L}$ ), and the difference value was about 0.3472 $\mathrm{mmol} / \mathrm{L}$. The upper reaches of Miaowei were currently building hydropower station, the area was temporarily considered as natural rivers, with DIC content of $2.6160 \mathrm{mmol} / \mathrm{L}$. Difference of UGGQ and DGGQ was higher because long impounding time and flow rate, as well as UNZD and DNZD. DIC content of remaining points were in similar position, about $2.10 \sim 2.30 \mathrm{mmol} / \mathrm{L}$.

In summary, DIC content in the middle and lower reaches of the Lancang River from north to south gradually decreased, and DIC content at upstream of the dam is lower than downstream of $r$ the dam. In addition, due to its special geographical location (in Nuozhadu reservoir), DIC content was generally low throughout the year.

\subsection{Vertical Variation of DIC Content in Nuozhadu Reservoir}

In order to further analyze the change of DIC content in vertical section, we took Nuozhadu reservoir as an example and measured the surface water at upstream the dam, 20-meter-deep, 50-meter-deepin September and October respectively, and the analysis results were showed in Figure 4.

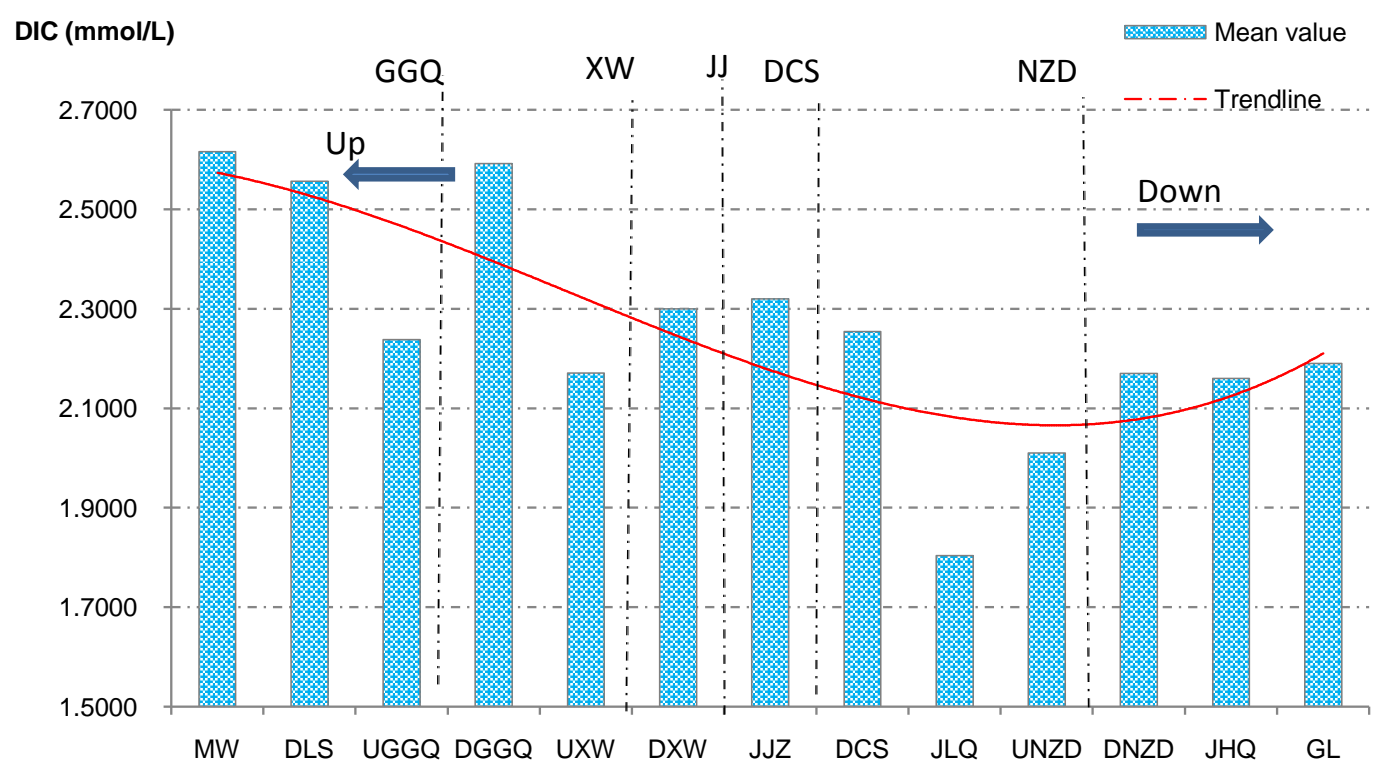

Figure 3. Spatial variation of DIC in the middle and lower reaches of the Lancang River in 2016. 
Through the above data analysis, it can be seen that the distribution of DIC content at upstream of the Nuozhadu Dam was stratified, that is, DIC content of the surface water was lower than that of deeper water. The study pointed out that the reason of DIC change should be that the surface water photosynthesis was more intense, while deeper water felt less light irradiation, and the photosynthesis was relatively weak [21]. So the surface water was mainly about photosynthesis, while deep water was mainly about breathing with the less consumption of $\mathrm{CO}_{2}$, which made DIC content in surface water lower than deeper water.

\subsection{Correlation Analysis of Water Environment Factors}

The natural environment will be presented with different environmental characteristics depending on the season, such as temperature, turbidity, DIC content will be also different. In this paper, software (SPSS) was used to analyze the water environmental factors (temperature, $\mathrm{pH}, \mathrm{ORP}$, conductivity, turbidity) and DIC content. The conclusions are as follows (Table 1).

After correlation analysis of DIC and its water environment factors, the DIC content has significantly passive correlation with temperature $(P<0.05)$, had high-positive correlation with the conductivity $(P<0.05)$ and high-passive correlation with the turbidity $(P<0.05)$, however the correlation with $\mathrm{pH}$ value and ORP were not significant at 0.05 level.

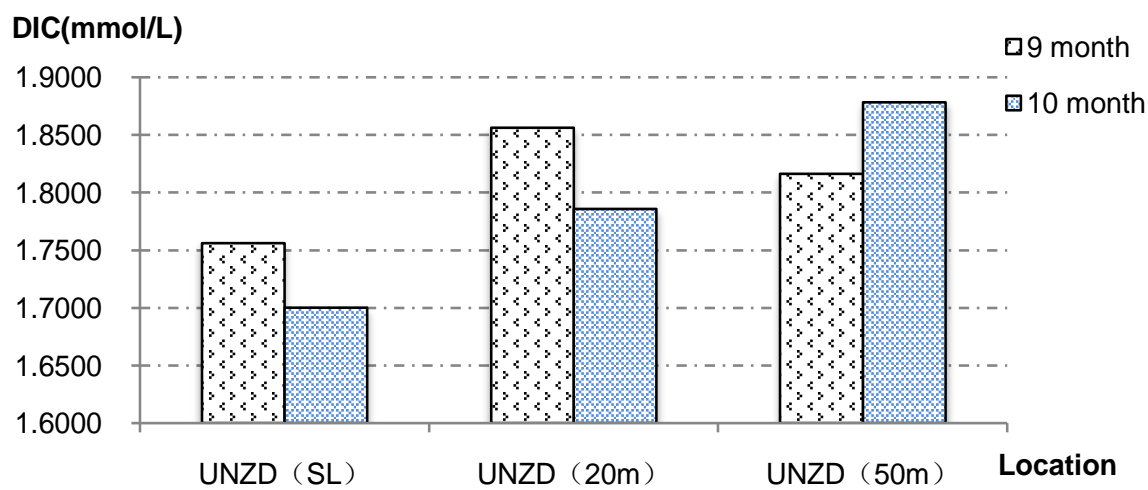

Figure 4. Vertical changes of DIC content in Nuozhadu reservoir.

Table 1. Correlation analysis of DIC and its water environment factors in the middle and lower reaches of Lancang River.

\begin{tabular}{ccccccc}
\hline & DIC & Tem & pH value & ORP & Cond & Turd \\
\hline DIC & 1 & & & & & \\
Tem & $-0.634^{* *}$ & 1 & & & & \\
pH value & -0.140 & -0.079 & 1 & & & \\
ORP & -0.199 & -0.044 & $-0.455^{* *}$ & 1 & & \\
Cond & $0.802^{* *}$ & $-0.730^{* *}$ & -0.112 & -0.096 & 1 & \\
Turd & $-0.249^{*}$ & 0.069 & -0.044 & $0.267^{*}$ & -0.167 & 1 \\
\hline
\end{tabular}

${ }^{\star}$ Significant correlation at 0.05 level (bilateral). ${ }^{*}$ Significant correlation at 0.01 level (bilateral). 
Among these water environment factors, temperature had high-passive correlation with the conductivity at 0.01 level, ORP had high-passive correlation with the $\mathrm{pH}$ value, and high-positive correlation with the turbidity, which was consistent with the facts. The study of conductivity showed that the conductivity had a high correlation with temperature, the changes of temperature will cause changes in conductivity. Studies on the Oxido-reduction Potential also showed that the ORP was closely related to the temperature, $\mathrm{pH}$, reversibility of chemical reactions and other factors.

So the water temperature, conductivity and turbidity were important factors affecting DIC content of water, they affected the changes and distribution of DIC content in water, while the effect of $\mathrm{pH}$ and ORP was relatively small.

\section{Discussions and Conclusions}

\subsection{Discussions}

The change of DIC content can characterize the biogeochemical processes such as photosynthesis, respiration and decomposition of organic matters in river and reservoir. The study showed that the change of DIC content was related to the photosynthesis and respiration, release and absorption of $\mathrm{CO}_{2}$ of aquatic organisms, precipitation and dissolution of calcium carbonate, input of tributary and exogenous matters and so on [22] [23]. Degradation and mineralization of organic matter in water also affected DIC content. Parts of results about DIC are shown in Table 2.

Table 2. DIC content of some rivers and reservoirs.

\begin{tabular}{|c|c|c|}
\hline River & $\mathrm{DIC}(\mathrm{mmol} / \mathrm{L})$ & References \\
\hline Amazon River & $0.96-1.2$ & Ternon et al., 2000 \\
\hline Mississippi River & $3.6-3.84$ & Cai, 2003 \\
\hline Indus River & 3.36 & Cosa et al., 1983 \\
\hline Gatami River & $2.08-3.0$ & Bouillons, 2003 \\
\hline The Ganges & $2.4-2.52$ & Cosa et al., 1983 \\
\hline The Yangtze River & 2.1312 & Wu et al., 2007 \\
\hline The Yellow River & 3.48 & Cauwet and Mackenzie, 1993 \\
\hline Zhujiang River & $1.44-1.8$ & Cai et al., 2004 \\
\hline Yellow River Basin & 3.6 & Xia Bin, 2010 \\
\hline Haihe River Basin & 4.8 & Xia Bin, 2010 \\
\hline The Luan River & 4.8 & Xia Bin, 2010 \\
\hline Estuary area of Yellow River & $3.6744-5.754$ & Liu et al., 2010 \\
\hline Hongjiadu Reservoir & 2.19 & Yu et al., 2008 \\
\hline Maotiaohe River Basin & $1.35-3.98$ & Li et al., 2009 \\
\hline The Jialing River Cascade Reservoir & $0.41-3.674$ & Li et al., 2015 \\
\hline The Yangtze River & 1.72 & Sivaji Patra et al., 2010 \\
\hline Wujiang River & 2.715 & Liu et al., 2007 \\
\hline Three Gorges Reservoir (upstream of dam) & $1.9-2.4$ & Wu et al., 2012 \\
\hline
\end{tabular}


According to the measured data, DIC content in the middle and lower reaches of the Lancang River varied from $1.1840 \mathrm{mmol} / \mathrm{L}$ to $3.1440 \mathrm{mmol} / \mathrm{L}$, with a mean of $2.2155 \mathrm{mmol} / \mathrm{L}$. Compared with rivers $(1.26 \mathrm{mmol} / \mathrm{L} \sim 5.28 \mathrm{mmol} / \mathrm{L})$ of the karst area in the Southwest, the content of DIC was slightly lower, then compared with rivers of the non-karst area, such as The Yangtze River (1.72 $\mathrm{mmol} / \mathrm{L})$, DIC content was higher. Tao et al. (2015) studied the chemical weathering process in the Sanjiang of southwest (Jinshajiang, Lancangjiang and Nujiang) watersheds in 2015 [24]. The results showed that the river basin in the southwest of Sanjiang River was controlled by complex lithology, and the Jinsha River was mainly about $\mathrm{Na}-\mathrm{Ca}-\mathrm{Cl}-\mathrm{HCO}_{3}$, which was related to the dissolution of salt minerals in the upper reaches of the basin. The Lancang and Nujiang Rivers are dominated by $\mathrm{Ca}-\mathrm{HCO}_{3}$, which showed the effect of carbonate and silicate mineral dissolution.

Therefore, a large part of DIC in the Lancang River was contributed by the erosion and chemical weathering, so the basin topography, geological conditions will have some impact on DIC content. In addition, according to the study, compared with the tributary of Yangtze River-Wujiang with the DIC content of $2.7150 \mathrm{mmol} / \mathrm{L}$ and Jialing River with cascade reservoir whose content ranged from $0.4100 \sim 3.6740 \mathrm{mmol} / \mathrm{L}$ (if regional terrain of the southwestern region is relatively similar), DIC content of the Lancang River Basin was almost the same, then compared with the undeveloped river, DIC content changed significantly. This indicates that the dam construction had an interception effect on DIC in river.

\subsubsection{Temporal Regime}

DIC content in dry season (spring, autumn and winter) in the middle and lower reaches of the Lancang River was significantly higher than that of the rainy season (summer). The rule was similar to that of study on Jialing River Basin of Li (2015) in 2008, and a study showed the same seasonal variation about Wujiang and Yuanjiang Rivers, as well as study on Hongjiadu Reservoir of the upper wujiang [25] [26]. Similar results were found in the Three Gorges Reservoir [27]. There are two main reasons: firstly, the rainfall increased greatly in summer, inport of rainwater to river would lead to attenuation, DIC content reduced in the meantime; secondly, with strong sunlight and proper temperature, the photosynthesis of aquatic organisms would be more strong and $\mathrm{CO}_{2}$ in river water would be consumed greatly, which also led to a decrease of DIC content in summer.

\subsubsection{Spatial Distribution}

Seeing from the space, DIC content from upstream to downstream in the middle and lower reaches of the Lancang River gradually decreased, and DIC content at upstream of the dam was lower downstream of the dam. The construction of cascade dams and climate change might be a reason. As a result of the dam interception, the river flowed slowly into the reservoir with large amount of water, 
water DIC content would be reduced surely. However, the water potential at downstream of the dam was no longer gentle with large flow, the $\mathrm{CO}_{2}$ exchange between the water-gas interface was more frequent, and DIC content in the water was also increased.

\subsubsection{Influencing Factors}

The change of DIC content in each sampling point has its own characteristics. On the one hand, the import and input of the three tributaries and exogenous matters in the lower reaches of the Lancang River will result in increase of DIC because of a large amount of carbonate and silicate mineral. The soil DIC (decomposition of organic matters in watershed) with the rainfall and the upstream precipitation of calcium carbonate will also lead to changes of DIC content. On the other hand, the more complex spatial changes are similar to the Jialingjiang Cascade Reservoir due to some natural factors and dam construction. In addition, difference between scheduling mode and construction time of cascade reservoir may also have effects.

Compared with some similar rivers which had been built cascade reservoirs, DIC content was at similar level. And the lake effect of the middle and lower reaches of the Lancang River was not obvious, DIC content at upstream of dam had a slight stratification.

In addition, the study of $\mathrm{Yu}$ on three reservoirs (Hongjiadu Reservoir, Dongfeng Reservoir, Wujiangdu Reservoir), which have different ages, showed that DIC content of Hongjiadu Reservoir was lower than Dongfeng Reservoir, $\mathrm{Wu}$ jiangdu Reservoir was the highest [28]. That is, the long the interception time and the lower the location, the higher DIC content. The operation time had positive correlation with DIC content. For example, Dachaoshan station had higher eutrophication level, as well as its DIC content, while Nuozhadu station was lower.

\subsection{Conclusions}

The content of DIC in the middle and lower reaches of the Lancang River varied from $1.1840 \mathrm{mmol} / \mathrm{L}$ to $3.1440 \mathrm{mmol} / \mathrm{L}$, with a mean value of about 2.2155 $\mathrm{mmol} / \mathrm{L}$. At a timescale, there are dry season (spring, autumn and winter) > rainy season (summer). At a space scale, the DIC content of the middle and lower reaches of the Lancang River gradually decreased from north to south, and each reservoir had the same characteristics, that is, DIC content at upstream of dam was lower than downstream of dam. Compared with some similar rivers which had been built cascade reservoirs, DIC content was at a similar level. And the lake effect of the middle and lower reaches of the Lancang River was not obvious, DIC content at upstream of dam had a slight stratification.

The water temperature, conductivity, turbidity were important factors affecting the DIC content of water, and the effect of oxidation and reduction potential (ORP) and $\mathrm{pH}$ on DIC were relatively small. In addition, watershed terrain, geological conditions, climate change and other natural factors would also affect 
the DIC content. And DIC content was also related to the dam construction, photosynthesis and respiration, $\mathrm{CO}_{2}$ release and absorption of aquatic organisms, precipitation and dissolution of calcium carbonate, input of tributary and exogenous matters and so on. These factors needed further analysis.

\section{Acknowledgements}

This work was supported by the Chinese National Natural Science Foundation of China (Grant No. 41571032, 41561144012, 41261100).

\section{References}

[1] IPCC (2013) Climate Change 2013: The Scientific Basis. Cambridge University Press, Cambridge, New York. https://www.ipcc.ch/report/ar5/wg1/

[2] Dai, X.S., Shi, G.Y. and Dong, M. (1998) Global Warming. China Meteorological Press, Beijing.

[3] Ding, Y.H. and Geng, Q.Z. (1998) Atmosphere, Oceans, Human Activities and Climate Change. China Meteorological Press, 24, 12-17. http://www.doc88.com/p-7418726744557.html

[4] Heimann, M. (1997) A Review of The Global Carbon Cycle and Foresight of Agrhenius and Hoghum 100 Years ago. AMB10. Journal of Human Environment, 26, 17-24. http://www.doc88.com/p-0731511781756.html

[5] Zhang, Z.G. and Hu, Y.B. (2016) Progress of Carbon Cycle Research on Land Soil. Soil and Water Conservation Bulletin, 35, 339-345. http://www.doc88.com/p-578321825846.html

[6] Liu, C.Q. (2009) Biogeochemical Processes and Matter Cycle of the Earth's Surface-The Basin Weathering of South-West Karst Area and Nutrients Elements Cycle. Science Press, Beijing, 169-192.

[7] Liu, C.Q., Wang, F.S. and Wang, Y.C. (2009) Responses of Aquatic Environment to River Damming-From the Geochemical View. Resources and Environment in the Yangtze Basin, 18, 384-396. http://www.doc88.com/p-1167193429432.html

[8] Peng, X., Liu, C.Q. and Wang, B.L. (2014) The Impact of Damming on Geochemical Behavior of Dissolved Inorganic Carbon in a Karst River. Science China Press, 2014, 59, 366-373. http://www.doc88.com/p-3466767007518.html

[9] Sivaji, P., Liu, C.Q., Li, S.L., et al. (2010) A Geochemical Study on Carbon Cycling in the Changjiang Estuary. Earth and Environment, 38, 409-413. http://www.docin.com/p-1228639853.html

[10] Xia, B. and Zhang, L.J. (2011) Carbon Distribution and Fluxes of 16 Rivers Discharging into the Bohai Sea in Summer. Acta Oceanologica Sinica, 30, 43-54.

http://www.docin.com/p-796712039.html https://doi.org/10.1007/s13131-011-0118-3

[11] Chen, J., Wang, F., Xia, X., et al. (2002) Major Element Chemistry of the Changjiang (Yangtze River). Chemical Geology, 187, 231-255. http://www.doc88.com/p-3307765435048.html https://doi.org/10.1016/S0009-2541(02)00032-3

[12] He, D.M, Feng, Y. and Gan, S. (2006) Cross-Border Hydrological Effect of Hydropower Development in the Mainstream of Lancang River. Science Bulletin, B07, 14-20. http://www.cnki.com.cn/article/cjfdtotal-kxtb2006s2003.htm

[13] Kang, B., He, D., Perrett, L., et al. (2009) Fish and Fisheries in the Upper Mekong: 
Current Assessment of the Fish Community, Threats and Conservation. Reviews in fish Biology and Fisheries, 19, 465-480.

http://www.doc88.com/p-1866910883010.html https://doi.org/10.1007/s11160-009-9114-5

[14] Li, L.J, Li, H.B., Wang, J., et al. (2002) Analysis on Hydrological and Water Quality Character and Their Spatial and Temporal Distribution in Lancangjiang River. Scientia Geographica Sinica, 22, 49-56. http://www.docin.com/p-691804945.html

[15] Lu, X.X., Li, S.Y., He, M., et al. (2011) Seasonal Changes of Nutrient Fluxes in the Upper Changjiang Basin: An Example of the Longchuanjiang River, China. Journal of Hydrology, 405, 344-351. http://www.doc88.com/p-3746661407086.html https://doi.org/10.1016/j.jhydrol.2011.05.032

[16] Fu, K.D., Su, B., He, D.M. and Lu, X.X. (2012) Pollution Assessment of Heavy Metals along the Mekong River and Dam Effects. Journal of Geographical Sciences, 22, 874-884. http://www.doc88.com/p-706860158536.html https://doi.org/10.1007/s11442-012-0969-3

[17] Fu, K.D., He, D.M. and Li, S.J. (2006) Downstream Sediment Response of the Lancang River under the Hydropower Development. Science Bulletin, 7, 100-105. http://www.docin.com/p-1264689237.html

[18] Ba, C.Z. and Li, Y. (2009) Phytoplankton Community Composition and Change in Reservoir Cascade Hydropower of Lancang River. Environmental Science Survey, 28, 18-21. http://www.doc88.com/p-2941205583589.html

[19] Wang, H.Z., Liu, Y.D. and Shen, Y.W. (2004) Preliminary Research on Water Bloom of Dinophyceae in Yunnan Manwan Hydropower Station Reservoir. Acta Hydrobiologica Sinica, 28, 213-215. http://www.doc88.com/p-7116856115893.html

[20] Chen, Q., Kong, X.S., et al. (2000) Basic Data Compendium of the Lancang River-Mekong River Basin. Yunnan Science and Technology Press, Kunming.

[21] Wu, Q. X., Han, G.L. and Tang, Y. (2012) Temporal and Spatial Variation of Water Chemistry and Dissolved Inorganic Carbon Isotope Characterization in Three Gorges Reservoir. Acta Scientiae Circumstantiae, 32, 654-661. http://lib.cqvip.com/qk/91840X/201203/40976293.html

[22] Li, X.D., Liu, X.L., et al. (2015) Spatial and Seasonal Variation of Dissolved Inorganic Carbon Isotope Compositions in the Cascade Reservoirs of the Jialing River. Journal of Shanghai University (Natural Science), 21, 286-293.

http://www.docin.com/p-1333193393.html

[23] Li, G.R., Liu, C.Q., Chen, C., et al. (2009) Dissolve Inorganic Carbon and Its Carbon Isotope Composition in Cascade Reservoir of the Maotiao River during Summer and Autumn. Environmental Science, 30, 2891-2897. http://www.doc88.com/p-9005926172157.html

[24] Tao, Z.H., et al. (2015) Chemical Weathering in the Three Rivers (Jingshajiang, Lancangjiang, and Nujiang) Watershed, Southwest China. Chinese Journal of Ecology, 34, 2297-2308. http://www.hsgj168.com/Article/CJFDTotal-STXZ201508031.htm

[25] Liu, Z.Y. (2014) Carbon Transport and Flux in the Yellow River Estuary. http://www.doc88.com/p-3059729593637.html

[26] Meybeek, M. (1993) Riverine Transport of Atmospheric Carbon: Sources, Global Typology and Budget. Water, Air, \& Soil Pollution, 70, 443-463. https://link.springer.com/chapter/10.1007\%2F978-94-011-1982-5_31 https://doi.org/10.1007/BF01105015 
[27] Yu, Y.X., Wang, F.S., et al. (2009) Response of Dissolved Inorganic Carbon and its Isotopic Spatial and Temporal Characteristics to the Earlier Reservoir Process: A Case Study on a New Reservoir (Hongjiadu). Acta Mineralogica Sinica, 29, 268-274. http://www.doc88.com/p-704221193003.html

[28] Yu, Y.X., Liu, C.Q., Wang, F.S., et al. (2008) Dissolve Inorganic Carbon and Its Isotopic Differentiation in Cascade Reservoir of Wujiang Basin. Chinese Science Bulletin, 53, 1935-1941. http://jz.docin.com/p-225903780.html

\section{Scientific Research Publishing}

Submit or recommend next manuscript to SCIRP and we will provide best service for you:

Accepting pre-submission inquiries through Email, Facebook, LinkedIn, Twitter, etc. A wide selection of journals (inclusive of 9 subjects, more than 200 journals)

Providing 24-hour high-quality service

User-friendly online submission system

Fair and swift peer-review system

Efficient typesetting and proofreading procedure

Display of the result of downloads and visits, as well as the number of cited articles

Maximum dissemination of your research work

Submit your manuscript at: http://papersubmission.scirp.org/

Or contact jwarp@scirp.org 